OPEN ACCESS

Edited by:

Ann Marie Reed,

Duke University, United States

Reviewed by:

Zhe-Xiong Lian,

South China University of Technology,

China

Lei Zhang,

Chinese Academy of Medical

Sciences and Peking Union Medical

College, China

*Correspondence:

Jun Peng

junpeng88@sina.com.cn

Ming Hou

houming@medmail.com.cn

Specialty section:

This article was submitted to Autoimmune and Autoinflammatory

Disorders,

a section of the journal

Frontiers in Immunology

Received: 02 September 2018 Accepted: 19 February 2019

Published: 18 March 2019

Citation:

Wang X, Li L, Wang Y, Li X, Feng Q,

Hou Y, Ma C, Gao C, Hou M and

Peng J (2019) High-Dose

Dexamethasone Alters the Increase in

Interleukin-16 Level in Adult Immune

Thrombocytopenia.

Front. Immunol. 10:451.

doi: 10.3389/fimmu.2019.0045

\section{High-Dose Dexamethasone Alters the Increase in Interleukin-16 Level in Adult Immune Thrombocytopenia}

\author{
Xinru Wang ${ }^{1,2}$, Lizhen $L^{3}{ }^{3}$, Yuanjian Wang ${ }^{4}$, Xin $L^{3}{ }^{3}$, Qi Feng ${ }^{1}$, Yu Hou ${ }^{1}$, Chunhong $\mathrm{Ma}^{5}$, \\ Chengjiang $\mathrm{GaO}^{5}$, Ming $\mathrm{Hou}^{3 *}$ and Jun Peng ${ }^{1 *}$ \\ 1 Department of Haematology and Qilu Hospital, Shandong University, Jinan, China, ${ }^{2}$ Department of Haematology, \\ Liaocheng People's Hospital, Liaocheng, China, ${ }^{3}$ Shandong Provincial Key Laboratory of Immunohematology, Qilu Hospital, \\ Shandong University, Jinan, China, ${ }^{4}$ West China School of Medicine, Sichuan University, Jinan, China, ${ }^{5}$ Department of \\ Immunology, Shandong University School of Medicine, Jinan, China
}

Adult primary immune thrombocytopenia (ITP) is an autoimmune-mediated haemorrhagic disorder. Interleukin-16 (IL-16) can directly affect cellular or humoural immunity by mediating the cellular cross-talk among $T$ cells, B cells and dendritic cells. Several studies have focused on IL-16 as an immunomodulatory cytokine that takes part in Th1 polarization in autoimmune diseases. In this study, we investigated IL-16 expression in the bone marrow supernatant and plasma of ITP patients and healthy controls. What's more, we detected IL-16 expression in ITP patients with the single-agent 4-day high-dose dexamethasone (HD-DXM) therapy. In patients with active ITP, bone marrow supernatant and plasma IL-16 levels increased $(P<0.05)$ compared with those of healthy controls. In the meantime, the mRNA expression in BMMCs (pro-IL-16, caspase-3) and PBMCs (pro-IL-16, caspase-3 and T-bet) of ITP patients was increased $(P<0.05)$ relative to those of healthy controls. In patients who responded to HD-DXM therapy, both plasma IL-16 levels and gene expression in PBMCs (pro-IL-16, caspase-3, and T-bet) were decreased $(P<0.05)$. In summary, the abnormal level of IL-16 plays important roles in the pathogenesis of ITP. Regulating Th1 polarization associated with IL-16 by HD-DXM therapy may provide a novel insight for immune modulation in ITP.

Keywords: adult immune thrombocytopenia, high-dose dexamethasone, Interleukin-16, caspase-3, Th1 polarization

\section{INTRODUCTION}

Adult primary immune thrombocytopenia (ITP) is an autoimmune-mediated haemorrhagic disorder in which platelets are destroyed by specific antibodies directed against platelet surface membrane glycoproteins (GPs) and prematurely cleared by macrophages in the reticuloendothelial system (1). The pathophysiology of ITP is characterized by excessive platelet destruction and a decrease in platelet production. The traditional mechanism of platelet destruction was GP-specific antibody mediated platelet clearance. Besides, skewed balance of T helper cell type 1 (Th1) to T helper cell type 2 (Th2) (2,3), reduced and defective capability of regulatory T cells $(4,5)$, abnormal Th17 and Th22 cells (6), cytotoxic T lymphocyte (CTL)-mediated platelet destruction (7), and altered levels of cytokines including IL-11, IL-18, IL-27, and IL-35 were involved in the pathogenesis of ITP (8-11). However, there are several abnormalities contributing to the pathophysiology of ITP that remain to be explored. 
Interleukin-16 (IL-16) is one of the first characterized cytokines with chemo-attractive activities for human $\mathrm{T}$ cells, which does not have any homology with other cytokines (12). The IL-16 gene is located on chromosome 15q26 in humans; it is translated into a 636-amino acid precursor, which was detected in both cytoplasm and nucleus (13). By activated caspase-3, pro-IL-16 is cleaved into a 121 -amino acid carboxyl-terminal fragment (C-IL-16) and an amino-terminal prodomain (N-IL16) in the cytoplasm, both of which have been found to be biologically active (14). The C-IL-16 is secreted into the plasma as a ligand for CD4/CD9 with chemo-attractant, growth factor, and differentiation factor capabilities on a variety of haematopoietic cell types that are involved in various specific autoimmune and inflammatory responses (15). The N-IL-16 is involved in the stabilization of $\mathrm{p} 27 \mathrm{Kip} 1$ protein and retention of $\mathrm{T}$ lymphocytes in the G0/G1 cell cycle phase $(16,17)$.

IL-16 is secreted by several leukocyte subsets, including T cells $(18,19)$, eosinophils (20), mast cells $(21,22)$, monocytes (23), and dendritic cells (24). Moreover, B cells constitutively express pro-IL-16. IL-16 mediates the cross-talk between $B$ cells and T cells via its chemotactic properties within lymph node follicles $(25,26)$. CD4, the common surface molecule, is known to be a receptor for IL-16 (27), while another surface molecule, CD9, has also been suggested as an alternate IL-16 receptor (28). Moreover, the effect of IL-16 on immune cells can be direct or indirect via the modulation of cytokines. For example, in addition to its role in regulating the recruitment and activation of $\mathrm{CD} 4^{+} \mathrm{T}$ cells to sites of inflammation (29), IL-16 stimulates the production of proinflammatory cytokines by monocytes, including interleukin 6 , tumor necrosis factor- $\alpha$, interleukin $1 \beta$, and interleukin 15 , with related downstream biological effects (30).

An increasing number of studies have demonstrated IL16 as an immunomodulatory cytokine that contributes to the regulation of recruitment and activation of $\mathrm{CD} 4^{+}$cell at sites with Th1 polarization in association with several autoimmune diseases, such as multiple sclerosis lesions (31) and autoimmune type 1 diabetes (32). The plasma level and gene expression of IL16 in childhood ITP was previously studied by our team. Newly diagnosed ITP patients with a Th1-dominant immune phenotype exhibit a high level of plasma IL-16 (by ELISA) and IL-16 gene expression (by DNA microarray analysis) (33).

Adult ITP is an autoimmune disease with Th1 superiority(2, 3). Similarly, the quantitative and qualitative abnormalities of immunological cells and immune dysfunction in patients with ITP can be, at least in part, attributed to IL-16, suggesting the potential value of IL-16 in prognostic evaluation in ITP. The roles of pro-IL-16/mature IL-16 in ITP remain unknown. In this present study, the levels of IL-16 in the plasma and bone marrow supernatants and mRNA expression of pro-IL-16, caspase- 3 and T-bet in the peripheral blood mononuclear cells (PBMCs) and bone marrow mononuclear cells (BMMCs) of patients with ITP were determined.

Treatment with high-dose dexamethasone (HD-DXM) as a single-agent for 4 days has been widely recognized as the first-line therapy for ITP patients in need of clinical management. Previous studies showed that HD-DXM could restore Th1/Th2 balance (34), expand regulatory cells including Tregs and MDSCs (35), suggesting the immunosuppressive function in recovery of ITP patients. However, the effects of HD-DXM on IL-16 expression remain unclear in ITP patients. Furthermore, we demonstrated changes in plasma levels of IL-16 and mRNA expression of pro-IL-16, caspase-3 and T-bet in PBMCs after HD-DXM, and these results may provide new insights into the mechanism for treatment of ITP with HD-DXM.

\section{MATERIALS AND METHODS}

\section{Patients and Controls}

Adult primary ITP patients with active disease were enrolled between May 2015 and December 2016 at the Department of Hematology, Qilu Hospital, Shandong University, Jinan, China. Patients were diagnosed according to recent guidelines (36) including clinical histories, somatoscopy, complete blood count and smear examination of peripheral blood. Patients and controls with complications such as Graves' disease, diabetes, hypertension, cardiovascular diseases, nervous system disease, neurological diseases, pregnancy, active infection, or connective tissue diseases, such as systemic lupus erythaematous (SLE), were excluded. The study was permitted by the Medical Ethical Committee of Qilu Hospital, Shandong University. Informed consent was obtained from all patients and controls before enrollment in the study.

Bone marrow samples were obtained from 23 patients, and 20 were used for ELISA ( 5 men and 15 women; range 24-63 years, median age 45 years; platelet counts ranging from 0 to $23 \times 10^{9} / \mathrm{L}$, median count $\left.9 \times 10^{9} / \mathrm{L}\right)$ and 14 for RT-PCR $(4$ men and 10 women; range 26-62 years, median age 41 years; platelet counts ranging from 0 to $23 \times 10^{9} / \mathrm{L}$, median count $9 \times$ $\left.10^{9} / \mathrm{L}\right)$. Peripheral blood samples were obtained from 64 patients, and among them, 21 received single-agent HD-DXM therapy. The peripheral blood samples were obtained before HD-DXM therapy and 28 days after HD-DXM administration for ELISA and RT-PCR. Complete response (CR) was defined as a platelet count $\geq 100 \times 10^{9} / \mathrm{L}$ and an absence of bleeding. Response $(\mathrm{R})$ was defined as a platelet count $\geq 30 \times 10^{9} / \mathrm{L}$, with at least a 2 -fold increase from baseline, and an absence of bleeding. No response $(\mathrm{NR})$ was defined as a platelet count $<30 \times 10^{9} / \mathrm{L}$, less than a 2 -fold increase from baseline, or bleeding (37). The main clinical characteristics of these patients are presented in Table 1. Among the peripheral blood samples, 52 were used for ELISA (18 men and 34 women; range 19-64 years, median age 42 years; platelet counts ranging from 1 to $26 \times 10^{9} / \mathrm{L}$, median count $10 \times 10^{9} / \mathrm{L}$ ) and 33 for RT-PCR (12 men and 20 women; range 19-69 years, median age 41 years; platelet counts ranging from 1 to $26 \times 10^{9} / \mathrm{L}$, median count $10 \times 10^{9} / \mathrm{L}$ ) and 33 for RT-PCR (12 men and 20 women; range 19-69 years, median age 41 years; platelet counts ranging from 1 to $26 \times 10^{9} / \mathrm{L}$, median count $10 \times 10^{9} / \mathrm{L}$ ).

The healthy adult control group consisted of 38 blood donors, and 26 of the samples were used for ELISA (10 men and 16 women; range 23-66 years, median age 41 years; platelet counts ranging from 105 to $263 \times 10^{9} / \mathrm{L}$, median count $\left.161 \times 10^{9} / \mathrm{L}\right)$ and 19 for RT-PCR (6 men and 13 women; range $23-68$ years, median age 42 years; platelet counts ranging from 105 to 290 $\times 10^{9} / \mathrm{L}$, median count $156 \times 10^{9} / \mathrm{L}$ ) In addition, there were 10 
TABLE 1 | Clinical characteristics of active ITP patients treated with HD-DMX.

\begin{tabular}{|c|c|c|c|c|c|}
\hline \multirow[t]{2}{*}{$\begin{array}{l}\text { Patient } \\
\text { NO. }\end{array}$} & \multirow{2}{*}{$\begin{array}{c}\text { Course of } \\
\text { disease } \\
\text { (month) }\end{array}$} & \multirow[t]{2}{*}{$\begin{array}{l}\text { Bleeding } \\
\text { symptoms }\end{array}$} & \multirow[t]{2}{*}{ Response } & \multirow{2}{*}{$\begin{array}{c}\begin{array}{c}\text { Platelet } \\
\text { counts }\left(\times 10^{9}\right)\end{array} \\
\text { Before }\end{array}$} & \multirow{2}{*}{$\begin{array}{l}\text { Counts } \\
\text { After }\end{array}$} \\
\hline & & & & & \\
\hline 1 & $O(10 d)$ & PT & CR & 1 & 144 \\
\hline 2 & 3 & EC & $\mathrm{R}$ & 20 & 92 \\
\hline 3 & $\mathrm{O}(3 \mathrm{~d})$ & PT, GH & $\mathrm{CR}$ & 7 & 195 \\
\hline 4 & $O(16 d)$ & No & NR & 23 & 20 \\
\hline 5 & 5 & PT, EP & $\mathrm{CR}$ & 7 & 131 \\
\hline 6 & $\mathrm{O}(3$ days) & PT, GH & $\mathrm{CR}$ & 1 & 158 \\
\hline 7 & 10 & No & $\mathrm{CR}$ & 27 & 135 \\
\hline 8 & 9 & No & NR & 6 & 11 \\
\hline 9 & 1 & PT, EC & $\mathrm{R}$ & 18 & 75 \\
\hline 10 & 7.5 & PT & $\mathrm{CR}$ & 11 & 195 \\
\hline 11 & 2 & PT, EP & CR & 8 & 141 \\
\hline 12 & 1 & PT, GH & CR & 1 & 102 \\
\hline 13 & 5 & PT & $\mathrm{CR}$ & 12 & 107 \\
\hline 14 & 1 & $\mathrm{EC}$ & $\mathrm{CR}$ & 5 & 195 \\
\hline 15 & 24 & No & $\mathrm{R}$ & 14 & 31 \\
\hline 16 & 0.5 & PT, GUH, GH & $\mathrm{CR}$ & 7 & 203 \\
\hline 17 & 12 & PT, EC & $\mathrm{R}$ & 10 & 44 \\
\hline 18 & 4 & $\mathrm{EC}, \mathrm{GH}$ & $\mathrm{CR}$ & 4 & 156 \\
\hline 19 & 9 & NO & $N R$ & 10 & 16 \\
\hline 20 & 4.5 & EC & CR & 9 & 159 \\
\hline 21 & 14 & GUH & $\mathrm{CR}$ & 17 & 174 \\
\hline Median & 4 & & & 9 & 135 \\
\hline
\end{tabular}

Male: 7 Median Age:51y (range 39-63)

Female:14 Median Age:36y (range 19-64)

bone marrow donors, and 10 samples were for ELISA test ( 3 men and 7 women; range $24-63$ years, median age 45 years; platelet counts ranging from 110 to $300 \times 10^{9} / \mathrm{L}$, median count of 172 $\times 10^{9} / \mathrm{L}$ ) and 9 for RT-PCR (3 men and 6 women; range 24-63 years, median age 45 years; platelet counts ranging from 110 to $295 \times 10^{9} / \mathrm{L}$, median count of $\left.172 \times 10^{9} / \mathrm{L}\right)$.

\section{Sample Preparation}

The peripheral blood or bone marrow samples were kept in heparin anticoagulant vacutainer tubes for no more than $2 \mathrm{~h}$ before isolation. Cell-free (platelet- and mononuclear cell-free) plasma or cell-free bone marrow supernatant samples were prepared using a standardized two-step separation method (700 g for $10 \mathrm{~min}$ and $1,300 \mathrm{~g}$ for $20 \mathrm{~min}$ ) as described previously to avoid the affection from cell lysis then settled in $-80^{\circ} \mathrm{C}$ until test $(38,39)$. PBMCs or BMMCs were isolated by density gradient centrifugation using Ficoll-Paque (Pharmacia Diagnostic, Uppsala, Sweden) and stored at $-80^{\circ} \mathrm{C}$ until RNA isolation.

\section{Enzyme-Linked Immunosorbent Assays}

Cell-free plasma IL-16 was measured using commercial Quantikine enzyme-linked immunosorbent assay (ELISA) kits (R\&D systems, Minneapolis, MN, USA) according to the manufacturer's instructions. The detection range for IL-16 is $31.2-2,000 \mathrm{pg} / \mathrm{mL}$ (sensitivity is $13.4 \mathrm{pg} / \mathrm{mL}$ ). The differences in bone marrow or plasma IL-16 levels between patients and healthy controls were compared using Mann-Whitney $U$-test. The plasma IL-16 levels before and after treatment were compared used paired $t$-test and Wilcoxon signed-rank test.

\section{RNA Isolation and Quantitative Real-Time Polymerase Chain Reaction Analysis}

Total RNA was isolated using TRIzol reagent (Invitrogen, Carlsbad, CA, USA), and converted to cDNA using PrimeScriptTM RT Master Mix (Perfect Real Time; Takara, Japan) according to the manufacturer's instructions. The mRNA expression of IL-16, Caspase-3, T-bet and $\beta$-actin (endogenous control) was quantified using SYBR Green Real-time PCR Master Mix (Toyobo, Japan) on an ABI PRISM 7,500 Sequence Detection System (Applied Bio-system, Foster City, CA, USA). The primers for all mRNA assays were intron spanning. The sequences of the amplification primers for human pro-IL-16, Caspase-3, T-bet, and $\beta$-actin are listed in Table 2. Each sample was analyzed in triplicate. The PCR amplification was performed for 40 cycles after initial denaturation $\left(95^{\circ} \mathrm{C}, 5 \mathrm{~min}\right)$ with the following parameters: denaturation at $95^{\circ} \mathrm{C}$ for $15 \mathrm{~s}$, annealing at $60^{\circ} \mathrm{C}$ (pro-IL-16, Caspase-3, T-bet, and $\beta$-actin) for $15 \mathrm{~s}$ and extension at $72^{\circ} \mathrm{C}$ for $45 \mathrm{~s}$, with temperature transition rates of $20^{\circ} \mathrm{C} / \mathrm{s}$. Fluorescence signals were acquired after extension at $72^{\circ} \mathrm{C}$. ABI Sequence Detection System software version (PE Applied Biosystems, Warrington, UK) was used to measure the cycle number at which fluorescence emission crossed the automatically determined $\mathrm{Ct}$ value. Because all steps were performed with equal efficiencies, the relative mRNA expression level of the target gene in each patient was calculated using the comparative cycle time $(\mathrm{Ct})$ method (40). Briefly, the $\mathrm{Ct}$ values of the targets were corrected by subtracting the $\mathrm{Ct}$ value of $\beta$-actin from these values, which generated the $\Delta \mathrm{Ct}$ value. From this $\Delta \mathrm{Ct}$ value, the relative expression level for each target gene compared to $\beta$-actin was calculated using the following formulation: Relative mRNA expression $=2^{--\mathrm{xCt}}$. Differences in mRNA expression between patients and controls were analyzed using the Mann-Whitney $U$-test. Differences in mRNA expression between pre-treatment and post-treatment samples were compared using Wilcoxon signed-rank test. The correlation between pro-IL-16, Caspase-3, and T-bet mRNA expression and plasma IL-16 level was determined using the linear regression test. Statistical analyses were performed at a 2 -tailed significance level of 0.05 .

\section{RESULTS}

\section{Response to HD-DXM Treatment}

Out of the 21 patients, 18 (6 males and 12 females, median age 41 years, range 19-64 years) responded effectively to the HDDXM therapy according to the standard definition (41). In these responders, platelet counts after treatment ranged from 31 to $203 \times 10^{9} / \mathrm{L}$, with a median count of $135 \times 10^{9} / \mathrm{L}$, as shown in Table 1. No hemorrhage or other complications were apparent after treatment. 
TABLE 2 | Primers and conditions for the qRT-PCR experiments performed in this study.

\begin{tabular}{|c|c|c|c|}
\hline Gene & $\begin{array}{l}\text { Primer } \\
\text { sequence }\left(5^{\prime}-3^{\prime}\right)\end{array}$ & $\begin{array}{c}\text { Annealing } \\
\text { temperature } \\
\left({ }^{\circ} \mathrm{C}\right)\end{array}$ & $\begin{array}{c}\text { Product } \\
\text { (bp) }\end{array}$ \\
\hline \multirow[t]{2}{*}{ IL-16 } & (F) 5'-ATGCCCGACCTCAACTCC-3' & & \\
\hline & (R) 5'-CTAGGAGTCTCCAGCAGC-3' & 60 & 389 \\
\hline \multicolumn{4}{|c|}{ Caspase-3 (F)5' -GGGGATCGTTGTAGAAGTCTAACT-3' } \\
\hline & (R)5' -GCATACAAGAAGTCGGCCTCCACT-3' & 60 & 159 \\
\hline \multirow[t]{2}{*}{ T-bet } & (F)5'-CATTGCCGTGACTGCCTACC-3' & & \\
\hline & (R)5' -GATGCTGGTGTCAACAGATGTG-3' & 60 & 121 \\
\hline \multirow[t]{2}{*}{$\beta$-actin } & (F)5' - TTGCCGACAGGATGCAGAA-3' & & \\
\hline & $(\mathrm{R}) 5^{\prime}$ - GCCGATCCACACGGAGTACT-3' & 60 & 101 \\
\hline
\end{tabular}

\section{Concentration of II-16 in the Bone Marrow Supernatant and Plasma of Patients With Active ITP and Controls}

The concentration of IL-16 in the bone marrow supernatants of ITP patients with active disease was significantly higher compared with that of the healthy controls (mean \pm SEM: 1686 $\pm 195.6(n=19)$ vs. $287.1 \pm 62.27(n=9), P=0.0002$, Mann-Whitney $U$-test) (Figure 1A).

The level of IL-16 in the plasma of ITP patients with active disease was significantly higher than that of healthy controls (mean \pm SEM: $187.7 \pm 24.06(n=52)$ vs. $57.14 \pm 4.344(n=$ 26), $P<0.0001$, Mann-Whitney $U$-test) (Figure 1B).

Further experiments were performed to investigate the possible effects of HD-DXM on the activity of IL-16 in ITP patients. The level of IL-16 in the plasma of ITP patients was detected before and 7 days after single-agent HD-DMX therapy for 4 days. The post-treatment plasma IL-16 level decreased significantly relative to that of pre-treatment level (mean \pm SEM: $222.9 \pm 33.09(n=21)$ vs. $90.17 \pm 13.36(n=21), P$ $=0.0003$, paired $t$-test) (Figure 1C). The level of IL-16 in the plasma of ITP patients before $(P<0.0001)$ and after $(P=$ $0.0143) \mathrm{HD}-\mathrm{DXM}$ treatment was significantly higher than that of healthy controls, $57.14 \pm 4.344(n=26)$, Mann-Whitney $U$-Test) (Figure 1D). The level of IL-16 in bone marrow supernatants was also downregulated after 4-day HD-DXM therapy (mean \pm SEM: $1646.16 \pm 578.11(n=7)$ vs. $1358.07 \pm 433.79(n=7), P=0.016$, paired $t$-test) (Figure 1E).There was no correlation between IL16 levels in the bone marrow supernatants or plasma and platelet count (data not shown).

\section{mRNA Expression Levels of Pro-IL-16, Caspase-3 and T-Bet in ITP Patients and Controls}

To elucidate the elevated plasma concentration of IL-16 in patients with active ITP, we determined the mRNA expression of pro-IL-16, caspase-3, and T-bet. Previous studies have demonstrated that high mRNA expression of caspase- 3 is necessary for the processing and activation of pro-IL-16 (14). Therefore, we determined caspase- 3 mRNA expression in our study. Several studies have demonstrated that IL-16 could skew immune responses toward a Th1 response $(42,43)$. Therefore, Tbet mRNA expression was also analyzed in our study to further evaluate the relationship between IL-16 and Th1 deviation in ITP Patients. Relative expression of mRNAs was calculated using $2^{-\Delta C T}$, and then the means were compared using $t$-test or MannWhitney $U$-test depending on the variance.

In accordance with the concentration of IL-16 in the bone marrow supernatants, the pro-IL-16 mRNA expression of BMMCs in patients with active ITP was significantly upregulated compared with that of healthy controls $(1.317 \pm 0.3074$ $(n=14)$ vs. $0.1182 \pm 0.7577(n=9), P=0.0012)$; caspase-3 mRNA were significantly higher in ITP patients compared with that in healthy controls $(0.1194 \pm 0.0797(n=14)$ vs. $0.006919 \pm$ 0.001468 ( $n=9), P=0.0298)$ (Figure 2A).

Consistent with the plasma IL-16 level, the relative amount of mRNA of pro-IL-16 and caspase- 3 of PBMCs in patients with active ITP was $0.09917 \pm 0.03048(n=33, P<0.0001)$ and $0.07495 \pm 0.03843(n=33, P<0.0001)$ relative to that in healthy controls $(0.02230 \pm 0.006397$ and $0.009746 \pm 0.001849$, respectively; $n=19$ ). However, both pro-caspase 3 and active caspase 3 protein levels have no significant difference in ITP patients compared with healthy control (Supplemental Figure). Our previous study has shown that T-bet mRNA expression was statistical higher in patients with active ITP than that in normal controls (44), which was in accordance with our present results where T-bet mRNA expression was significantly higher in patients with active ITP than that in controls $(0.02148$ $\pm 0.01098 \%(n=33)$ vs. $0.002748 \pm 0.0005696(n=19)$, $P<0.0001$ ) (Figure 2B). Pro-IL-16, Caspase-3 and T-bet mRNA expression after 4 days of treatment with HD-DMX as a single agent compared with that before treatment was significantly decreased, although the corresponding values were not statistically higher than those of healthy controls (Figure 2C).

\section{Correlation of Plasma IL-16 Level With Pro-IL-16, Caspase-3 and T-Bet mRNA Levels in ITP Patients}

The correlation between the plasma IL-16 concentration and pro-IL-16, caspase-3 and T-bet mRNA levels was analyzed in ITP patients. The results demonstrated that the mRNA levels of the three detected factors were positively correlated with plasma IL-16 concentration $\left(r^{2}=0.5846, P<0.0001, r^{2}=0.3980\right.$, $P<0.0001$, and $r^{2}=0.3145, P=0.0001$ for pro-IL-16, caspase- 3 , and T-bet, respectively; linear regression; Figures 2D-F.

Taken together, in this study we demonstrated that the IL-16 levels in the bone marrow supernatants and plasma of adult ITP patients with active disease were significantly higher than those in healthy controls. The mRNA expression of IL-16, caspase-3 and T-bet in PBMCs and BMMCs were statistically higher than the corresponding mRNA expression in healthy controls. Single-agent HD-DMX treatment for 4 days decreased the plasma IL-16 level and downregulated mRNA expression of IL-16, caspase-3, and T-bet in ITP patients PBMCs. Furthermore, the plasma IL-16 levels were positively correlated with pro-IL-16, caspase-3, and T-bet mRNA expression. 

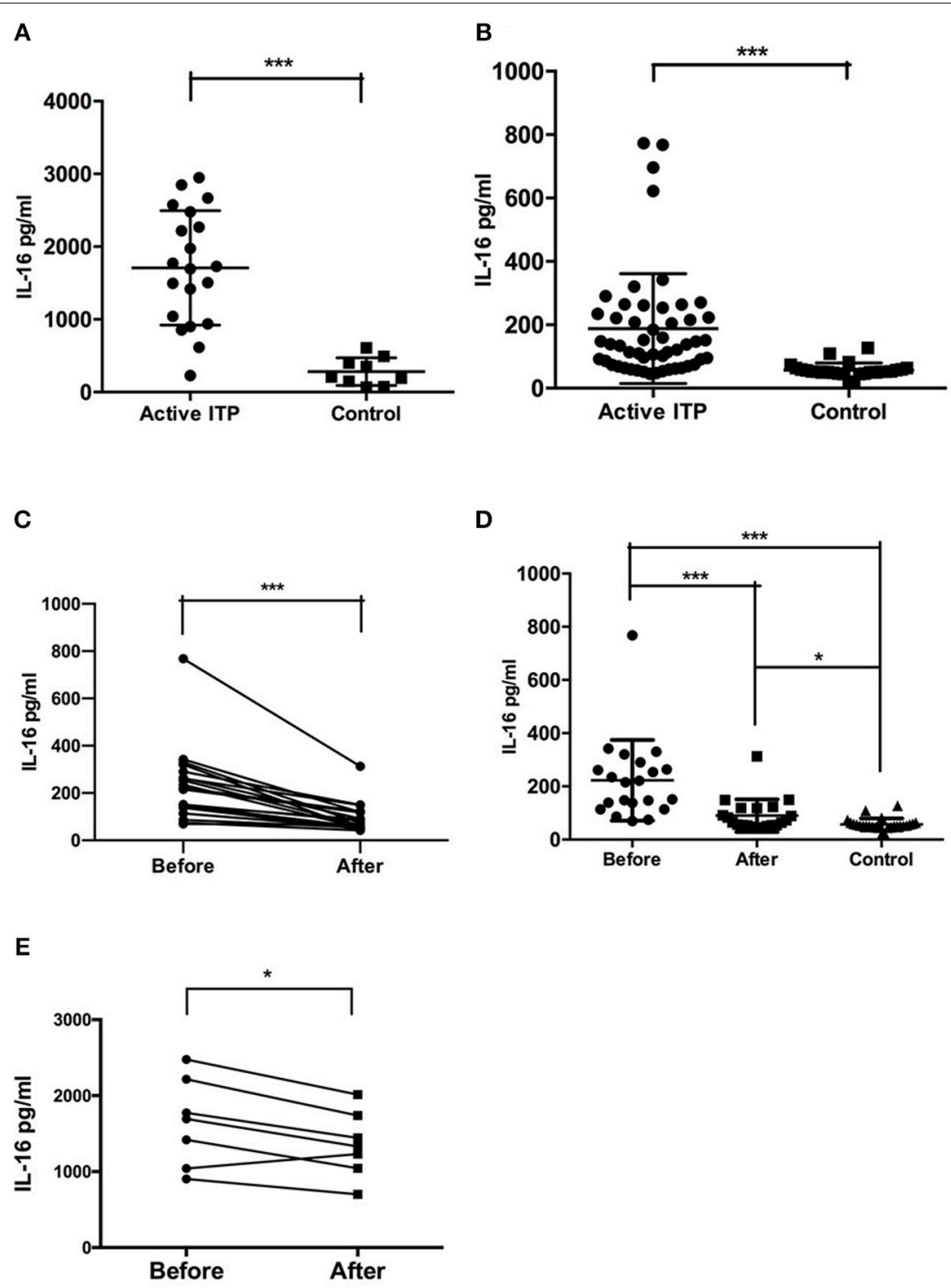

FIGURE 1 | Bone marrow supernatant and plasma concentrations of IL-16 in active ITP and controls. (A) IL-16 levels in bone marrow in ITP patients and healthy controls were analyzed by ELISA. IL-16 levels were significantly higher in active ITP patients than healthy controls. (B) IL-16 levels in plasma in ITP patients and healthy controls were analyzed by ELISA. IL-16 levels were significantly higher in active ITP patients than healthy controls. ${ }^{* \star *} P<0.001$. (C) Plasma concentration of IL-16 in active ITP before HD-DXM, after HD-DXM and controls. IL-16 levels in plasma in active ITP before HD-DXM and after HD-DXM were analyzed by ELISA. IL-16 levels were significantly higher in active ITP before HD-DXM than after HD-DXM treatment. (D) IL-16 levels in plasma in active ITP before HD-DXM, after HD-DXM and in controls were analyzed by ELISA. IL-16 levels were significantly higher in active ITP before HD-DXM than after HD-DXM treatment, and were significantly higher after HD-DXM treatment than in healthy controls. (E) IL-16 levels in bone marrow supernatants in active ITP before and after HD-DXM treatment were analyzed by ELISA. IL-16 levels were significantly decreased after HD-DXM treatment. ${ }^{\star \star \star} P<0.001 ;{ }^{\star} P<0.05$.

\section{DISCUSSION}

Our results provide evidence that IL-16 contributes to the development of ITP. The mechanism by which IL-16 promotes ITP requires a considerable amount of work to be fully understood. IL-16 is a special cytokine with two isoforms, namely, N-IL-16 and C-IL-16, and both of these isoforms have been shown to have modulatory functions for growth and activation of immune cell (14). Elevation of C-IL-16 levels at sites of inflammation may contribute to Th1 advantage, in consistent with the previously reported role of this protein in other Th1associated immune diseases $(42,45)$. Lynch,et al. demonstrated that IL-16 preferentially induces Th1 cell migration with help from CCR5. Th1 subset specificity is attributable to an increase in IL-16 binding (46). Recently, our team had demonstrated that in ITP patients, CCR5 expression in PBMCs of patients with active ITP was significantly higher than in PBMCs of healthy controls. These results may explain how C-IL-16 alters the Th1/Th2 balance in ITP patients (47). N-IL-16 is located both in the cytolymph, as a substrate for mature IL-16 following 


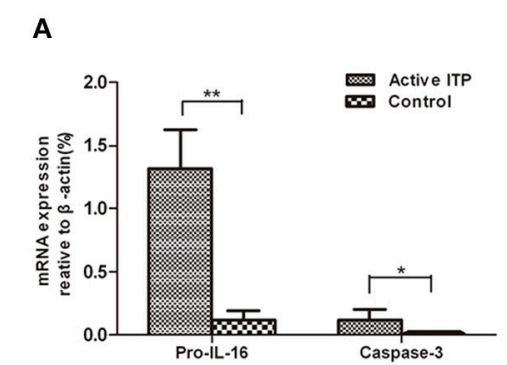

D

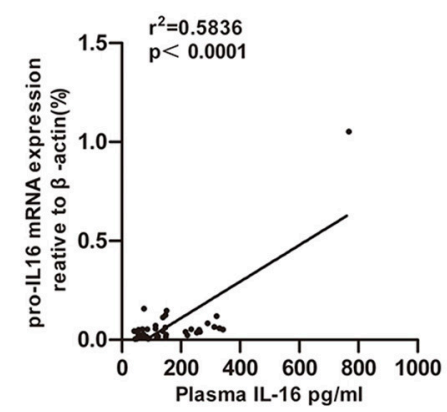

B

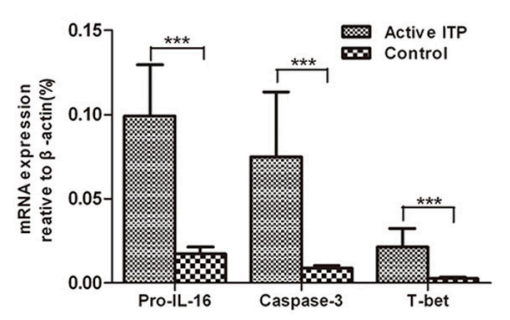

$E$

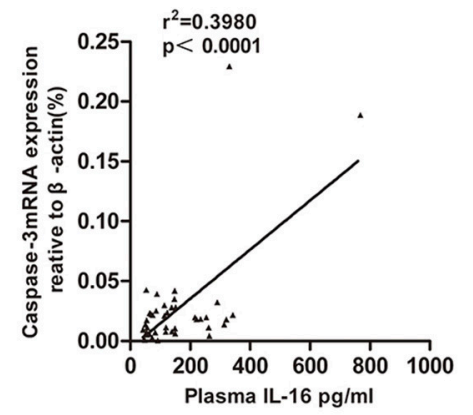

C

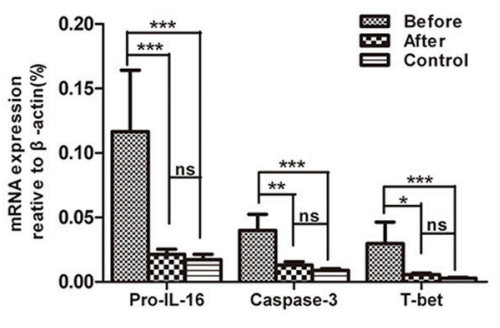

$\mathbf{F}$

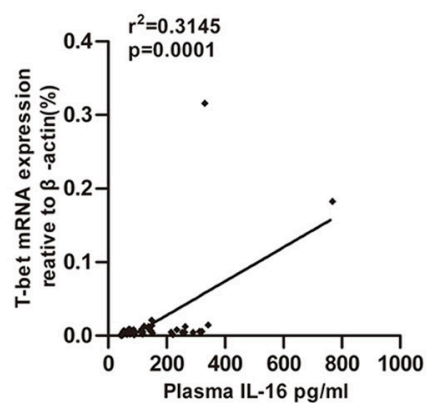

FIGURE 2 | Relative mRNA expression of pro-IL16, caspase-3 and T-bet in ITP patients with active disease and healthy controls. mRNA expression in bone marrow mononuclear cells (BMMCs) and peripheral blood mononuclear cells (PBMCs) from ITP patients and healthy controls were quantified by real-time PCR. Furthermore, correlations between plasma IL-16 and mRNA expression levels of pro-IL16, caspase-3 and T-bet in active ITP patients were calculated. (A) Relative mRNA expression of pro-IL16, caspase-3 in ITP patients with active disease and healthy controls in BMMCs; ${ }^{\star \star \star} P<0.001 ;{ }^{* \star} P<0.01 ;{ }^{\star} P<0.05$. (B) Relative mRNA expression of pro-IL16, caspase-3 and T-bet in PBMCs in ITP patients with active disease and healthy controls. ${ }^{* \star *} P<0.001 ;{ }^{* *} P<0.01$; ${ }^{*} P<0.05$. (C) mRNA expression of pro-IL16, caspase-3 and T-bet in active ITP before HD-DXM, after HD-DXM and controls. ${ }^{\star \star \star} P<0.001$; ${ }^{* \star} P<0.01$; ${ }^{*} P<0.05$. (D) Correlation between plasma and mRNA expression levels of IL-16 in active ITP patients. Plasma IL-16 levels and pro-IL-16 mRNA expression in PBMCs were determined by ELISA and real-time PCR. There was a positive correlation between the factors $\left(r^{2}=0.5846, P<0.0001\right.$; Pearson correlation analysis). (E) Correlation between plasma IL-16 levels and caspase-3 mRNA expression in active ITP patients. Plasma IL-16 levels and caspase-3 mRNA expression in PBMCs were determined by ELISA and real-time PCR. There was a positive correlation between the factors $\left(r^{2}=0.3980, P<0.0001\right.$; Pearson correlation analysis). (F) Correlation between plasma IL-16 levels and T-bet mRNA expression levels in active ITP patients. Plasma IL-16 levels and T-bet mRNA expression in PBMCs were determined by ELISA and real-time PCR. There was a positive correlation between the factors $\left(r^{2}=0.3145, P<0.0001\right.$; Pearson correlation analysis).

caspase- 3 dissociation, and in the cyteblast where it functions to weaken the cleavage of p27Kip1, a pivotal cell-cycle molecules (48). Meanwhile,the IL-16 expression was significantly downregulated by HD-DXM therapy. We suppose the role of decreased IL-16 in the pathogenesis of ITP might including: reducing the production of proinflammatory cytokines by monocytes (30); decreasing the generation of GP-specific antibody and correcting the imbalance of Th1/Th2 differentiation (31), (32).

Increasing evidence has shown that an abnormally strong Th1 response plays a central role in the pathogenesis of chronic ITP $(2,3)$. T-bet is a T-box family transcription factor whose expression is primarily limited to the immune system. It is present in early developing Th1 cells but is absent in developing Th2 cells (49). We also found high levels of T-bet mRNA expression of ITP patients and further determined that plasma IL-16 levels positively correlated with Th1 levels in these patients.

ITP is an organ-specific autoimmune disorder; complex interactions among antigen-presenting cells, $\mathrm{T}$ cells and $\mathrm{B}$ cells are pivotal to its pathogenesis. In particular, B cells not only produce immunoglobulin but also play an important immunoregulatory role in the pathophysiology of ITP (41). A study reported that IL-16 is necessary for B lymphocytes to attract dendritic cells and Th1 cells (25). A novel monoclonal anti-IL-16 antibody called 14.1, that combines with IL-16 and induces a conformational change in the IL-16 PDZ domain has been recently reported (50). When incubated with $\mathrm{CD}^{+}$cells, the 14.1 antibody was shown to reduce the Th1-type inflammatory response. In our future study, we will use an in vitro study system to test and verify if the anti-IL-16 antibody can be used to treat adult ITP.

Our data suggest that IL-16 plays an important role in the pathogenesis of ITP by polarization of Th1. Further, by modulating the abnormal IL-16 level associated with the Th1 imbalance via treatment with pulsed HD-DXM provided us with new insights into the immune regulatory mechanisms for the treatment of ITP.

\section{ETHICS STATEMENT}

This study was carried out in accordance with the recommendations of Medical Ethical Committee of Qilu Hospital, Shandong University with written informed consent from all subjects. All subjects gave written informed consent in accordance with the Declaration of Helsinki. The protocol was approved by the Medical Ethical Committee of Qilu Hospital, Shandong University. 


\section{AUTHOR CONTRIBUTIONS}

JP and XW designed research, analyzed data, and wrote the paper. LL, YW, and XL performed research, analyzed data. QF and $\mathrm{YH}$ performed research and wrote the paper. CM and CG evaluated the data and corrected the paper. $\mathrm{MH}$ reviewed the manuscript. All authors read and approved the final manuscript.

\section{ACKNOWLEDGMENTS}

This work was supported by grants from the Major Research plan of the National Natural Science Foundation of China (91442204),

\section{REFERENCES}

1. Berchtold P, Wenger M. Autoantibodies against platelet glycoproteins in autoimmune thrombocytopenic purpura: their clinical significance and response to treatment. Blood. (1993) 81:1246-50.

2. Semple JW, Milev Y, Cosgrave D, Mody M, Hornstein A, Blanchette V., et al. Differences in serum cytokine levels in acute and chronic autoimmune thrombocytopenic purpura: relationship to platelet phenotype and antiplatelet T-cell reactivity. Blood. (1996) 87:4245-4.

3. Panitsas FP, Theodoropoulou M, Kouraklis A, Karakantza M, Theodorou GL, Zoumbos NC., et al. Adult chronic idiopathic thrombocytopenic purpura (ITP) is the manifestation of a type-1 polarized immune response. Blood. (2004) 103:2645-7. doi: 10.1182/blood-2003-07-2268

4. Liu B, Zhao H, Poon MC, Han Z, Gu D, Xu M., et al. Abnormality of $\mathrm{CD} 4(+) \mathrm{CD} 25(+)$ regulatory $\mathrm{T}$ cells in idiopathic thrombocytopenic purpura. Eur. J. Haematol. (2007) 78:139-43. doi: 10.1111/j.1600-0609.2006.00780.x

5. Yu J, Heck S, Patel V, Levan J, Yu Y, Bussel JB., et al. Defective circulating CD25 regulatory $T$ cells in patients with chronic immune thrombocytopenic purpura. Blood. (2008) 112:1325-8. doi: 10.1182/blood-2008-01-135335

6. Zhang J, Ma D, Zhu X, Qu X, Ji C, Hou M. Elevated profile of Th17, Th1 and Tcl cells in patients with immune thrombocytopenic purpura. Haematologica. (2009) 94:1326-9. doi: 10.3324/haematol.2009.007823

7. Olsson B, Andersson PO, Jernås M, Jacobsson S, Carlsson B, Carlsson LM., et al. T-cell-mediated cytotoxicity toward platelets in chronic idiopathic thrombocytopenic purpura. Nat Med. (2003) 9:1123-4. doi: 10.1038/nm921

8. Yao R, Lin Y, Li Q, Zhou X, Pan X, Bao Y., et al. Downregulation of Tbet/GATA-3 ratio induced by IL-11 treatment is responsible for Th1/Th2 balance restoration in human immune thrombocytopenic purpura (ITP). J Thrombosis Thrombol. (2014) 38:183-9. doi: 10.1007/s11239-013-1036-3

9. Shan NN, Zhu XJ, Peng J, Qin P, Zhuang XW, Wang HC., et al. Interleukin 18 and interleukin 18 binding protein in patients with idiopathic thrombocytopenic purpura. Br J Haematol. (2009) 144:755-61. doi: 10.1111/j.1365-2141.2008.07520.x

10. Liu XG, Ren J, Yu Y, Sun L, Shi Y, Qin P., et al. Decreased expression of interleukin-27 in immune thrombocytopenia. British J Haematol. (2011) 153:259-67. doi: 10.1111/j.1365-2141.2011.08614.x

11. Sun T, Zhang D, Yang Y, Zhang X, Lv C, Fu R., et al. Interleukin 35 may contribute to the loss of immunological self-tolerance in patients with primary immune thrombocytopenia. Br J Haematol. (2015) 169: 278-85. doi: 10.1111/bjh.13292

12. Cruikshank W, Kornfeld H, Berman J, Chupp G, Keane J, Center D. Biological activity of interleukin-16. Nature. (1996) 382:501-2.

13. Baier M, Bannert N, Werner A, Lang K, Kurth R. Molecular cloning, sequence, expression, and processing of the interleukin 16 precursor. Proce Natl Acad Sci USA. (1997) 94:5273-77.

14. Zhang Y, Center DM, Wu DM, Cruikshank WW, Yuan J, Andrews DW., et al. Processing and activation of pro-interleukin-16 by caspase-3. J Biol Chem. (1998) 273:1144-9. doi: 10.1074/jbc.273.2.1144
National Natural Science Foundation of China (81770133, 81770114 and 81800112), National Natural Science Foundation for Distinguished Young Scholars of China (81125002), State Key Clinical Specialty of China for Blood Disorders, Natural Science Foundation of Shandong Province (ZR2017PH022, ZR2017PH041) and Tai Shan Scholar Foundation.

\section{SUPPLEMENTARY MATERIAL}

The Supplementary Material for this article can be found online at: https://www.frontiersin.org/articles/10.3389/fimmu. 2019.00451/full\#supplementary-material

15. Richmond J, Tuzova M, Cruikshank W, Center D. Regulation of cellular processes by interleukin-16 in homeostasis and cancer. J Cell Physiol. (2014) 229:139-47. doi: 10.1002/jcp.24441

16. Zhang Y, Kornfeld H, Cruikshank WW, Kim S, Reardon CC, Center DM. Nuclear translocation of the N-terminal prodomain of interleukin-16. J Biol Chem. (2001) 276:1299-303. doi: 10.1074/jbc.M008513200

17. Wilson KC, Cruikshank WW, Center DM, Zhang Y. Prointerleukin16 contains a functional $\mathrm{CcN}$ motif that regulates nuclear localization. Biochemistry. (2002) 41:14306-12. doi: 10.1021/bi020163v

18. Chupp GL, Wright EA, Wu D, Vallen-Mashikian M, Cruikshank WW, Center DM., et al. Tissue and T cell distribution of precursor and mature IL-16. J Immunol. (1998) 161:3114-9.

19. Wu DM, Zhang Y, Parada NA, Kornfeld H, Nicoll J, Center DM, et al. Processing and release of IL-16 from CD4+ but not CD8+ T cells is activation dependent. J Immunol. (1999) 162:1287-93.

20. Lim KG, Wan HC, Bozza PT, Resnick MB, Wong DT, Cruikshank WW., et al. Human eosinophils elaborate the lymphocyte chemoattractants. IL-16 (lymphocyte chemoattractant factor) and RANTES. J Immunol. (1996) 156:2566-70.

21. Lorentz A, Schwengberg S, Sellge G, Manns MP, Bischoff SC. Human intestinal mast cells are capable of producing different cytokine profiles: role of $\operatorname{IgE}$ receptor cross-linking and IL-4. J Immunol J Immunol. (2000) 164:43-8. doi: 10.4049/jimmunol.164.1.43

22. Rumsaeng V, Cruikshank WW, Foster B, Prussin C, Kirshenbaum AS, Davis TA., et al. Human mast cells produce the CD4+ T lymphocyte chemoattractant factor, IL-16. J Immunol. (1997) 159:2904-10.

23. Elssner A, Doseff AI, Duncan M, Kotur M, Wewers MD. IL16 is constitutively present in peripheral blood monocytes and spontaneously released during apoptosis. J Immunol. (2004) 172:7721-25. doi: 10.4049/jimmunol.172.12.7721

24. Kaser A, Dunzendorfer S, Offner FA, Ryan T, Schwabegger A, Cruikshank WW., et al. A role for IL-16 in the cross-talk between dendritic cells and T cells. J Immunol. (1999) 163:3232-8.

25. Kaser A, Dunzendorfer S, Offner FA, Ludwiczek O, Enrich B, Koch RO., et al. B lymphocyte-derived IL-16 attracts dendritic cells and Th cells. J Immunol. (2000) 165:2474-80. doi: 10.4049/jimmunol.165.5.2474

26. Kramer MF, Mack B, Rasp G. Immunohistological expression of interleukin 16 in human tonsils. Arch Otolaryngol. (2001) 127:1120-5. doi: 10.1001/archotol.127.9.1120

27. Cruikshank WW, Berman JS, Theodore AC, Bernardo J, Center DM. Lymphokine activation of T4+ T lymphocytes and monocytes. J Immunol. (1987) 138:3817-23.

28. Qi JC, Wang J, Mandadi S, Tanaka K, Roufogalis BD, Madigan MC., et al. Human and mouse mast cells use the tetraspanin CD9 as an alternate interleukin-16 receptor. Blood. (2006) 107:135-42. doi: 10.1182/blood-2005-03-1312

29. Center DM, Kornfeld H, Cruikshank WW. Interleukin-16. Int J Biochem Cell Biol. (1997) 29:1231-4. doi: 10.1016/S1357-2725(97)00053-8 
30. Mathy NL, Scheuer W, Lanzendörfer M, Honold K, Ambrosius D, Norley S., et al. Interleukin-16 stimulates the expression and production of proinflammatory cytokines by human monocytes. Immunology. (2000) 100:63-9. doi: 10.1046/j.1365-2567.2000.00997.x

31. Skundric DS, Cai J, Cruikshank WW, Gveric D. Production of IL-16 correlates with CD4+ Th1 inflammation and phosphorylation of axonal cytoskeleton in multiple sclerosis lesions. J Neuroinflamm. (2006) 3:13. doi: 10.1186/1742-2094-3-13

32. Meagher C, Beilke J, Arreaza G, Mi QS, Chen W, Salojin K., et al. Neutralization of interleukin-16 protects nonobese diabetic mice from autoimmune type 1 diabetes by a CCL4-dependent mechanism. Diabetes. (2010) 59:2862-71. doi: 10.2337/db09-0131

33. Jernås $M$, Hou Y, Strömberg Célind F, Shao L, Nookaew I, Wang Q., et al. Differences in gene expression and cytokine levels between newly diagnosed and chronic pediatric ITP. Blood. (2013) 122:1789-92. doi: 10.1182/blood-2013-05-502807

34. Guo C, Chu X, Shi Y, He W, Li L, Wang L., et al. Correction of Th1-dominant cytokine profiles by high-dose dexamethasone in patients with chronic idiopathic thrombocytopenic purpura. J Clin Immunol. (2007) 27:557-62. doi: 10.1007/s10875-007-9111-1

35. Hou Y, Feng Q, Xu M, Li GS, Liu XN, Sheng Z., et al. Highdose dexamethasone corrects impaired myeloid-derived suppressor cell function via Ets1 in immune thrombocytopenia. Blood. (2016) 127:1587-97. doi: 10.1182/blood-2015-10-674531

36. Provan D, Stasi R, Newland AC, Blanchette VS, Bolton-Maggs P, Bussel JB., et al. International consensus report on the investigation and management of primary immune thrombocytopenia. Blood. (2010) 115:168-86. doi: 10.1182/blood-2009-06-225565

37. Rodeghiero F, Stasi R, Gernsheimer T, Michel M, Provan D, Arnold DM., et al. Standardization of terminology, definitions and outcome criteria in immune thrombocytopenic purpura of adults and children: report from an international working group. Blood. (2009) 113:2386-93. doi: 10.1182/blood-2008-07-162503

38. Goihl A, Rolle AM, Kähne T, Reinhold A, Wrenger S, Reinhold D. Methodologic issues in the measurement of interleukin-16 in clinical blood samples using immunoassays. Cytokine. (2012) 58:1-5. doi: 10.1016/j.cyto.2011.12.012

39. Reinhold D, Bank U, Bühling F, Junker U, Kekow J, Schleicher E., et al. A detailed protocol for the measurement of TGF-betal in human blood samples. J Immunol Methods. (1997) 209:203-6. doi: 10.1016/S0022-1759(97) 00160-9

40. Meijerink J, Mandigers C, van de Locht L, Tönnissen E, Goodsaid F, Raemaekers J. A novel method to compensate for different amplification efficiencies between patient DNA samples in quantitative real-time PCR. J Mol Diagnos. (2001) 3:55-61. doi: 10.1016/S1525-1578(10)60652-6
41. Cooper N, Bussel J. The pathogenesis of immune thrombocytopaenic purpura. Br J Haematol. (2006) 133:364-74. doi: 10.1111/j.1365-2141.2006.06024.x

42. Cruikshank WW, Lim K, Theodore AC, Cook J, Fine G, Weller PF., et al. IL-16 inhibition of CD3-dependent lymphocyte activation and proliferation. J Immunol. (1996) 157:5240-8.

43. Pinsonneault S, El Bassam S, Mazer B, Cruikshank WW, Laberge S. IL-16 inhibits IL-5 production by antigen-stimulated T cells in atopic subjects. $J$ Allergy Clinl Immunol. (2001) 107:477-82. doi: 10.1067/mai.2001.112373

44. Shan NN, Hu Y, Hou M, Gao J, Wang X, Liu X., et al. Decreased Tim-3 and its correlation with Th1 cells in patients with immune thrombocytopenia. Thrombosis Res. (2014) 133:52-56. doi: 10.1016/j.thromres.2013.10.029

45. Theodore AC, Center DM, Nicoll J, Fine G, Kornfeld H, Cruikshank WW. CD4 ligand IL-16 inhibits the mixed lymphocyte reaction. J Immunol. (1996) 157:1958-64.

46. Lynch EA, Heijens CA, Horst NF, Center DM, Cruikshank WW. Cutting edge: IL-16/CD4 preferentially induces Th1 cell migration: requirement of CCR5. J Immunol. (2003) 171:4965-8. doi: 10.4049/jimmunol.171.10.4965

47. Liu Z, Wang M, Zhou S, Ma J, Shi Y, Peng J., et al. Pulsed highdose dexamethasone modulates Th1-/Th2-chemokine imbalance in immune thrombocytopenia. J Translt Med. (2016) 14:301. doi: 10.1186/s12967-016-1064-9

48. Center DM, Cruikshank WW, Zhang Y. Nuclear pro-IL-16 regulation of $\mathrm{T}$ cell proliferation: p27(KIP1)-dependent G0/G1 arrest mediated by inhibition of Skp2 transcription. J Immunol. (2004) 172:1654-60. doi: 10.4049/jimmunol.172.3.1654

49. Szabo SJ, Kim ST, Costa GL, Zhang X, Fathman CG, Glimcher LH. A novel transcription factor, T-bet, directs Th1 lineage commitment. Cell. (2000) 100:655-69. doi: 10.1016/S0092-8674(00)80702-3

50. Hall G, Cullen E, Sawmynaden K, Arnold J, Fox S, Cowan R., et al. Structure of a potential therapeutic antibody bound to interleukin-16 (IL16): Mechanistic Insights And New Therapeutic Opportunities. J Biol Chem. (2016) 291:16840-8. doi: 10.1074/jbc.M115.709303

Conflict of Interest Statement: The authors declare that the research was conducted in the absence of any commercial or financial relationships that could be construed as a potential conflict of interest.

Copyright (c) 2019 Wang, Li, Wang, Li, Feng, Hou, Ma, Gao, Hou and Peng. This is an open-access article distributed under the terms of the Creative Commons Attribution License (CC BY). The use, distribution or reproduction in other forums is permitted, provided the original author(s) and the copyright owner(s) are credited and that the original publication in this journal is cited, in accordance with accepted academic practice. No use, distribution or reproduction is permitted which does not comply with these terms. 